\title{
High temperature corrosion behavior of superalloy GH984G in synthetic flue gases environments
}

\author{
G.M. LIU ${ }^{1}$ \& S.P. REN ${ }^{1}$,Q. LIANG ${ }^{2}$ \& H.C. YANG ${ }^{2}$,C.S. WANG ${ }^{3}$ \& L.Z. \\ $\mathrm{ZHOU}^{3}$ \\ ${ }^{1}$ School of Materials Science and Engineering, Nanchang Hangkong University, Nanchang, Jiangxi, \\ China \\ ${ }^{2}$ Material Research Institute, Dongfang Boiler Group Co.,Ltd, Zigong, Sichuang, China \\ ${ }^{3}$ Institute of Metal Research, Chinese Academy of Sciences, Shenyang, Liaoning, China
}

KEYWORD: USC boiler; GH984G; high temperature corrosion; flue gas

ABSTRACT: High temperature corrosion behavior of Ni-Fe-based Superalloy GH984G was studied in the synthetic flue gas environments with different $\mathrm{SO} 2$ concentration at $800^{\circ} \mathrm{C}$. The microstructure and composition of the scales were investigated by scanning electron microscope/energy dispersive spectroscope and X-ray diffraction. The Cr2O3-rich scale with a mount of $\mathrm{TiO} 2$ formed on the sample surface. With the SO2 increasing, corrosion became serious and more $\mathrm{TiO} 2$ was detected in the scale. Sulfides could be detected even the SO2 concentration decreased to $0.5 \%$.

\section{Introduction}

The aim of increasing the efficiency of future coal-fired power plants requires designs for more critical steam conditions. The requirement for high efficiency and reduced emissions requires the use of advanced ultra-supercritical (A-USC) conditions with steam temperature of up to $700 \sim 760^{\circ} \mathrm{C}$ and pressure of up to $35 \sim 37.5 \mathrm{MPa}$. The goal of A-USC is to generate $760^{\circ} \mathrm{C}$ steam, although the metal surface temperature of the key components including the superheater and reheater tubes will be $800{ }^{\circ} \mathrm{C}$ or even higher.

Ni-based superalloys are expected to be the best candidates for advanced ultra-supercritial (A-USC) steam boiler applications in coal-fired power generation system. GH984G (Ni-20.7Fe-20.9Cr-3.4(Mo+

$\mathrm{Nb})-2.3(\mathrm{Ti}+\mathrm{Al}), \mathrm{wt} . \%)$ alloy is a new Ni-Fe-Cr based wrought superalloy with high creep strength. This superalloy is a candidate for superheater and reheater tubes application due to its comprehensive mechanical properties and long-term thermal stability. The aim of the present work is to examine the corrosion resistance of this alloy in high temperature synthetic flue gases atmosphere.

\section{Experiments}

GH984 alloy was received from Institute of Metal Research, Chinese Academy of Science. Square specimens with dimensions of $10 \times 15 \times 3 \mathrm{~mm}$ were cut by the electrical-discharge method. The surfaces were ground down to $800 \mathrm{SiC}$ paper. The sample surfaces were cleaned in acetone and distilled water in an ultrasonic bath before testing. The synthetic flue gas was composed of: $15 \% \mathrm{CO}_{2}$, $3.5 \% \mathrm{O}_{2},(1 \%, 0.5 \%$ and $0.25 \%) \mathrm{SO}_{2}$, bal. $\mathrm{N}_{2}$. The gases flow was set to a rate of $20 \mathrm{~mL} / \mathrm{min}$, the test temperature was $800^{\circ} \mathrm{C}$.

After corrosion test, the surface morphology and phase composition of the specimens were investigated in scanning electron microscope (SEM) equipped with energy dispersive spectroscope (EDS) and in X-ray diffraction (XRD).

\section{Experiment results}

\section{Corrosion kinetics and corrosion equations of materials}

Fig. 1 shows the Corrosion kinetics of GH984G after exposed for $1000 \mathrm{~h}$ in the synthetic flue gas environments with different $\mathrm{SO}_{2}$ concentration. The fitting results are shown in Table 1. The corrosion of the samples in the test conditions for $1000 \mathrm{~h}$ is slight $\left(<0.6 \mathrm{mg} / \mathrm{cm}^{2}\right)$. The results showed that the samples had good corrosion resistance in fuel gases environment. 


\section{The phase composition and microstructure of corrosion products}

Fig. 2 shows the X-ray diffraction patterns of the samples corroded in synthetic flue gas with various $\mathrm{SO}_{2}$ concentrations. The XRD analysis revealed that
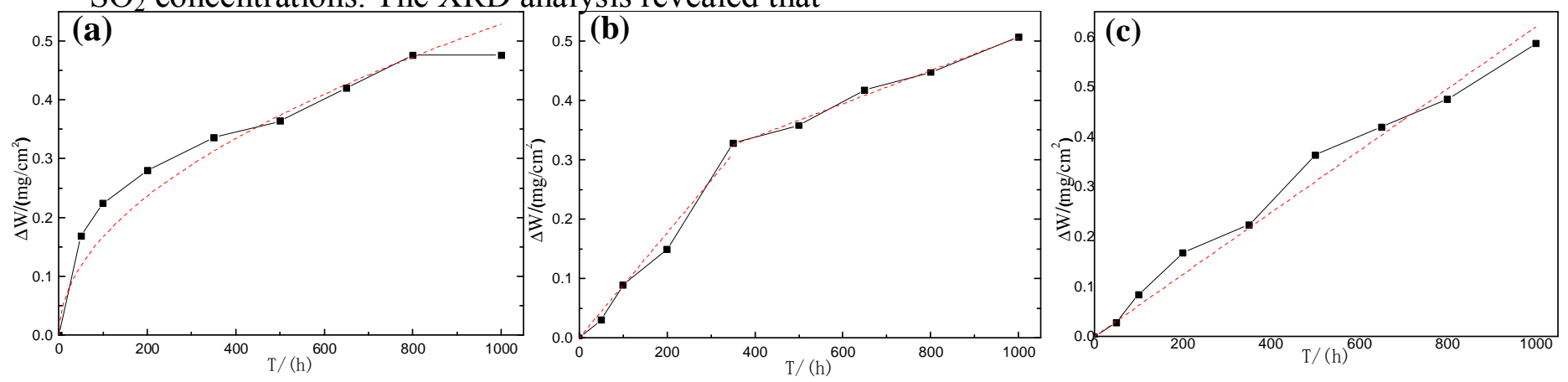

Figure 1. Corrosion kinetics and fitted curves of the samples in the various $\mathrm{SO}_{2}$ concentration. (a) $0.25 \% \mathrm{SO}_{2}$; (b) $0.5 \% \mathrm{SO}_{2} ;$ (c) $1 \% \mathrm{SO}_{2}$;

Table 1. Fitted results of samples under different corrosion conditions.

\begin{tabular}{lll}
\hline $\begin{array}{l}\mathrm{SO}_{2} \\
(\mathrm{vol} \%)\end{array}$ & $\begin{array}{l}\text { Fitted } \\
\text { equation }\end{array}$ & Correlation coefficients \\
\hline 0.25 & $\mathrm{y}^{2}=2 \mathrm{k}_{1} \mathrm{t}$ & $\mathrm{k}_{1}=1.396 \times 10^{-4}$ \\
0.5 & $\mathrm{y}=\mathrm{k}_{2} \mathrm{t}$ & $\mathrm{k}_{2}=8.85486 \times 10^{-4}$ \\
& $\mathrm{y}=\mathrm{k}_{3} \mathrm{t}+\mathrm{b}$ & $\mathrm{k}_{3}=2.79447 \times 10^{4} ; \mathrm{b}=0.2268$ \\
1 & $\mathrm{y}=\mathrm{k}_{4} \mathrm{t}$ & $\mathrm{k}_{4}=6.19936 \times 10^{-4}$ \\
\hline
\end{tabular}

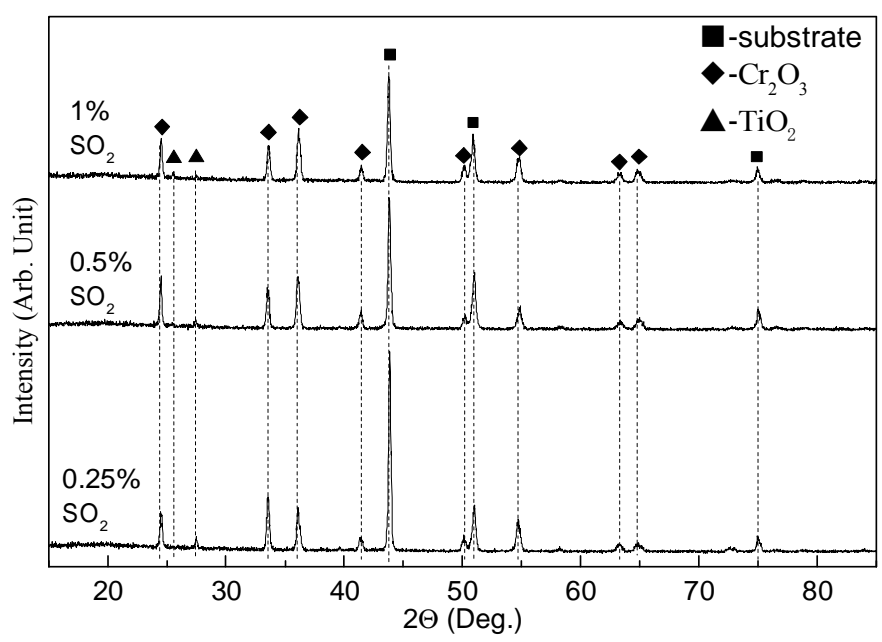

Figure 2. XRD pattern of the samples after corrosion $1000 \mathrm{~h}$.

the main corroded phases of all corroded samples were composed of $\mathrm{Cr}_{2} \mathrm{O}_{3}$ and $\mathrm{TiO}_{2}$.

Fig. 3 shows the surface microstructure corresponding EDS X-ray spectra of GH984G alloy corroded in synthetic flue gas with various $\mathrm{SO}_{2}$ concentrations. Some large grains (marked as $\mathrm{S}$ ) were observed on the sample surface. EDS analysis revealed that the large grains and other area (marked as $\mathrm{P}$ ) consisted of $\mathrm{Cr}$, Ti and $\mathrm{O}$. However, EDS results revealed that the Ti concentration decreased with the $\mathrm{SO}_{2}$ concentration increasing. When $\mathrm{SO}_{2}$ concentration reached $0.5 \%, \mathrm{~S}$ element could be detected on the sample surface.

Fig. 4 shows the cross-section and corresponding EDS X-ray spectra of the specimen corroded in synthetic flue gas with various $\mathrm{SO}_{2}$ concentrations. SEM observation revealed that continuous and compact scale formed on the sample surface. A larger number of needle-like corrosion regions were observed in the alloy substrate. Fig.4(a) shows the cross-section of the sample tested in the gases contains $0.25 \% \mathrm{SO}_{2}$, EDS analysis showed that $\mathrm{Ti}$ was not detected in the $\mathrm{Cr}_{2} \mathrm{O}_{3}$-rich scale, combining the results of the XRD and the EDS on the surface, we could conclude that the $\mathrm{TiO}_{2}$ formed 
on the sample surface. In the needle-like corrosion regions, $\mathrm{Ni}, \mathrm{Fe}, \mathrm{Cr}, \mathrm{Al}, \mathrm{S}$ and $\mathrm{O}$ was detected. Fig.4(b) shows the cross-section of the sample tested in the gases contain $0.5 \% \mathrm{SO}_{2}$, EDS identified that $\mathrm{Ti}$ existed in the corrosion scale $(2.02 \mathrm{wt} \%)$. Moreover, $\mathrm{S}$ was detected at the interface of scale/substrate. When $\mathrm{SO}_{2}$ concentration was $1 \%$, Ti was found in the corrosion scale $(3.50 \mathrm{wt} \%), \mathrm{S}$ mainly existed in the scale.

\section{Discussion}

Generally, $\mathrm{SO}_{2}$ could react with $\mathrm{O}_{2}$ and produce sulphur trioxide at high temperatures according to following reaction:

$\mathrm{SO}_{2}(\mathrm{~g})+\frac{1}{2} \mathrm{O}_{2}(\mathrm{~g})=\mathrm{SO}_{3}(\mathrm{~g}) \quad \Delta \mathrm{G}=-99000+93.95 \mathrm{~T} \mathrm{~J}$

However, thermodynamic calculation result indicates the above mentioned reaction was not favored at $800^{\circ} \mathrm{C}$. Therefore, the corrosion is mainly caused by oxidation and sulfur dioxide under the experiment conditions.

Table 2 shows the $\Delta G_{m}^{0}$ values of different oxides. All the data in this Table are calculated by the software HSC Chemistry 6 . According to Table 2 indicates that the affinity between metals and oxygen at $800^{\circ} \mathrm{C}$ decreased according to following sequence: $\mathrm{Al}, \mathrm{Ti}, \mathrm{Cr}, \mathrm{Fe}, \mathrm{Ni}$. Meanwhile, the composition and microstructure of the scale formed on the alloys is not only affected by thermodynamics driving force, but also affected by the content of metal in the alloy.

Considering that the content of $\mathrm{SO}_{2}$ was low in this test, $\mathrm{GH} 984$ alloy inevitably oxidized by $\mathrm{O}_{2}$. F. Abe et al reported that $\mathrm{Al}$ ions are virtually immobile in the scale and that the growth of $\mathrm{A}_{2} \mathrm{O}_{3}$ proceeds by inward diffusion of oxygen in the $\mathrm{Cr}_{2} \mathrm{O}_{3}$-rich scale at $800^{\circ} \mathrm{C}$. Therefore, $\mathrm{Al}$ was detected in the needle-like products in the substrate. However, the high mobility of Ti ions makes it poss-

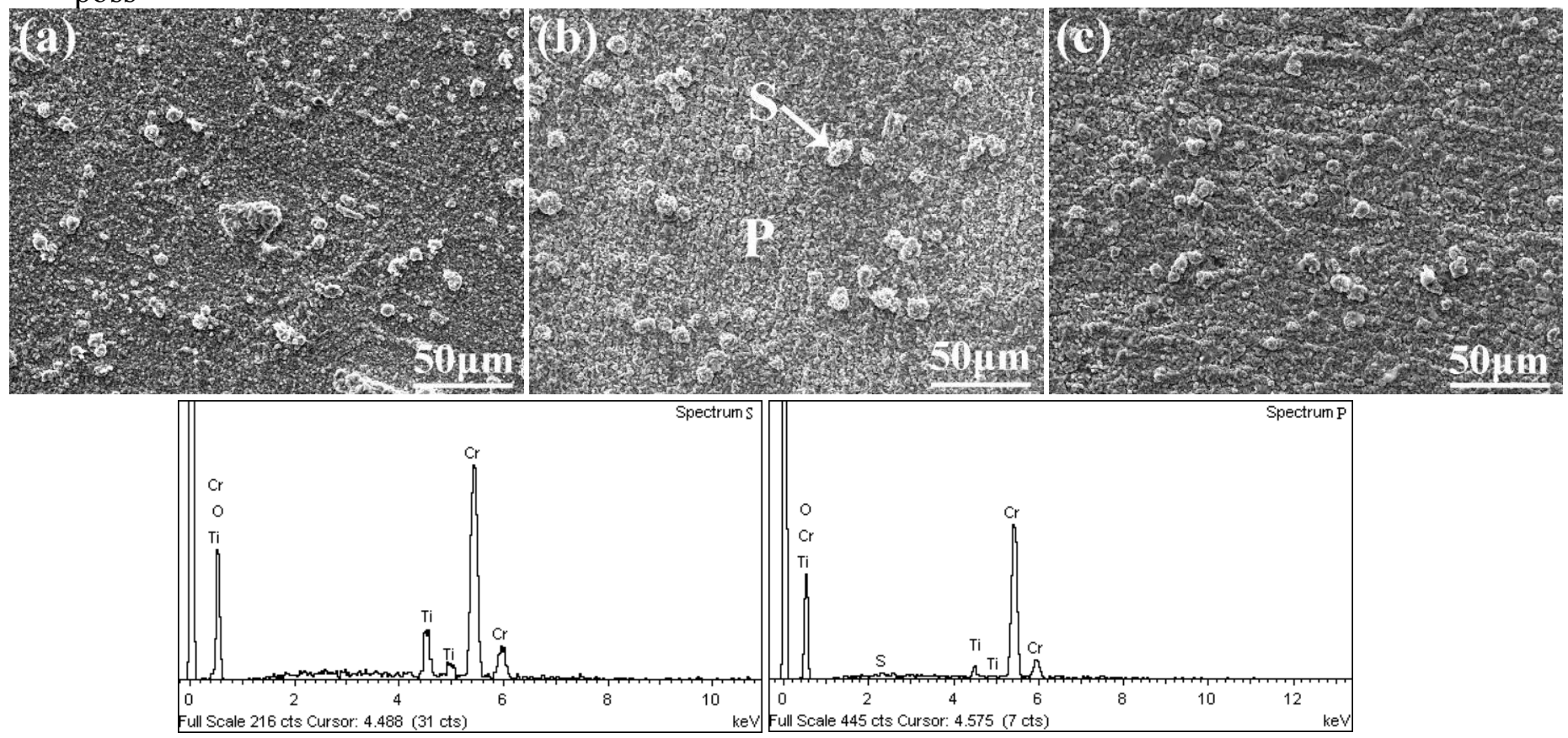

Figure 3. The surface microstructure and corresponding EDS X-ray spectra of samples corroded in synthetic flue gas for 1000h. (a) $0.25 \% \mathrm{SO}_{2}$; (b) $0.5 \% \mathrm{SO}_{2}$; (c) $1 \% \mathrm{SO}_{2}$; 


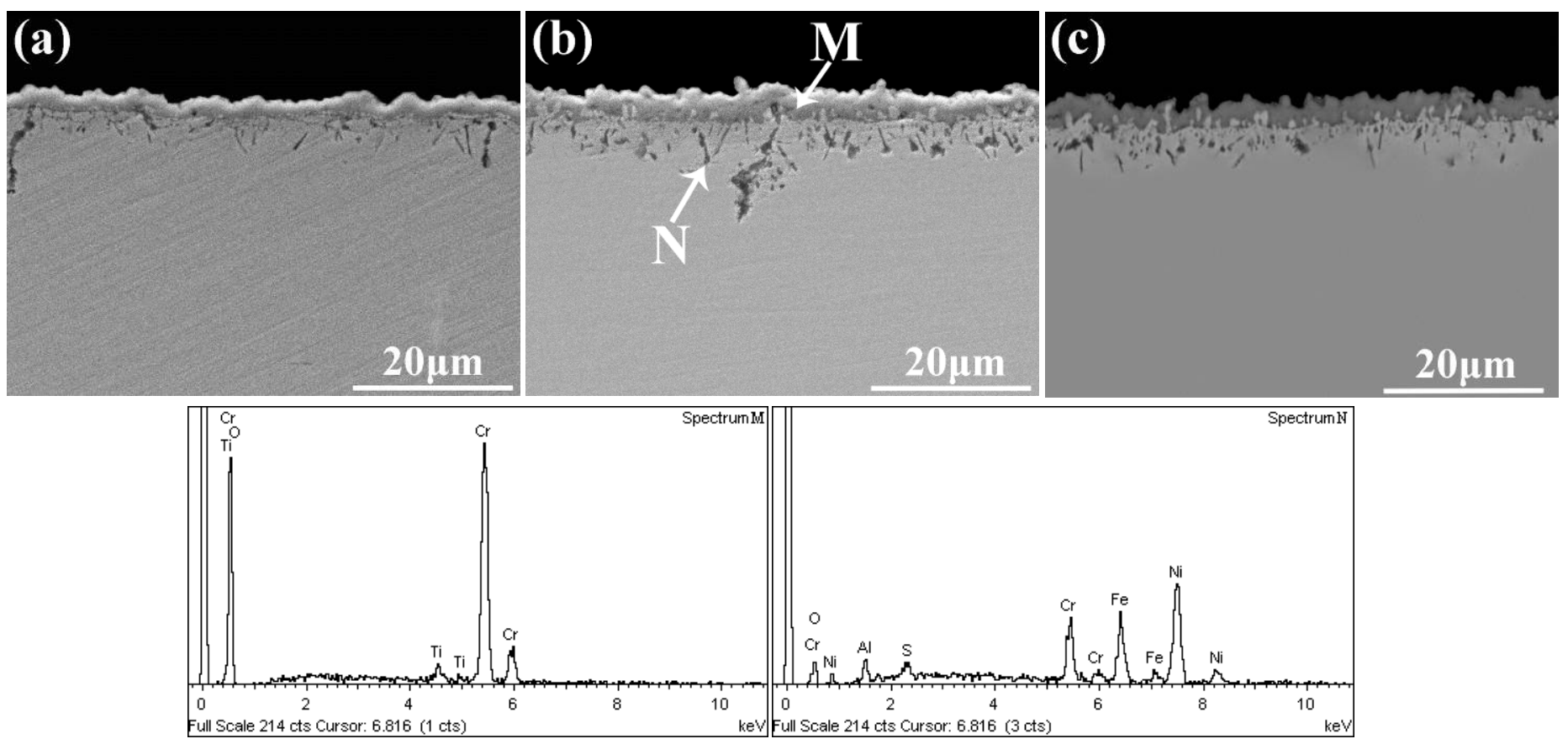

Figure 4. The cross-sections morphology and corresponding EDS X-ray spectra of samples corroded in synthetic flue gas for $1000 \mathrm{~h}$. (a) $0.25 \% \mathrm{SO}_{2}$; (b) $0.5 \% \mathrm{SO}_{2}$; (c) $1 \% \mathrm{SO}_{2}$;

Table 2. The calculated $\Delta G_{m}^{0}$ values of different oxide at $800^{\circ} \mathrm{C}$.

\begin{tabular}{cccccc}
\hline Oxide & $\mathrm{Al}_{2} \mathrm{O}_{3}$ & $\mathrm{TiO}_{2}$ & $\mathrm{Cr}_{2} \mathrm{O}_{3}$ & $\mathrm{Fe}_{2} \mathrm{O}_{3}$ & $\mathrm{NiO}$ \\
\hline $\begin{array}{c}\Delta G_{m}^{0} \\
(\mathrm{~kJ} / \mathrm{mol})\end{array}$ & -1336 & -749 & -853 & -541 & -142
\end{tabular}

ible to migrate through the $\mathrm{Cr}_{2} \mathrm{O}_{3}$ scale and to form $\mathrm{TiO}_{2}$ on the sample surface.

As mentioned above, $\mathrm{S}$ was detected in the scale by EDS, combining the corrosion kinetics, we could conclude that $\mathrm{SO}_{2}$ existed in synthetic flue gas led to corrosion accelerated. It can be seen that only formation of oxide and can proceed if suphur partial pressure are too low. When the samples tested in the gases with $0.25 \mathrm{vol} \% \mathrm{SO}_{2}$, No Sulphur was detected by the EDS. Actually, at high temperatures $\mathrm{SO}_{2}$ could lead corrosion of some metals according to reaction (1). If the suphur partial pressure was low enough, sulfides were instability, which would led to sulfides displace or decompose. Therefore, only oxides were detected in the scale when $\mathrm{SO}_{2}$ concentration was set to $0.25 \mathrm{vol} \%$. It is reported that the direct reaction of the $\mathrm{SO}_{2}$ with the metal has been considered rather than the reaction with, sulfur and oxygen, which accounted for the formation of the sulfide/oxide layer.

$2 \mathrm{bM}+\mathrm{SO}_{2}=2 \mathrm{M} \mathrm{b}+\frac{1}{2} \mathrm{~S}_{2}$

When $\mathrm{SO}_{2}$ concentration up to $0.5 \%$, the $\mathrm{S}$ was been found under the $\mathrm{Cr}_{2} \mathrm{O}_{3}$-rich scale, we can conclude that the internal sulfidation reaction occurred. When partial pressures increasing and scale became thicker on the sample surface, oxygen partial pressure would decrease, which could lead to local sulphur partial pressure increasing and formation of sulfide, especially, sulfide observed at the interface of scale/substrate. When $\mathrm{SO}_{2}$ concentration was $1 \%$, the $\mathrm{S}$ was been found on surface, scale, and the metal/scale interface. Under this condition, the following reaction probably occurred: $7 \mathrm{Cr}+3 \mathrm{SO}_{2}=2 \mathrm{Cr}_{2} \mathrm{O}_{3}+3 \mathrm{CrS} \quad \Delta G_{800}^{\theta}=-1236 \mathrm{KJ} / \mathrm{mol}$

According to above reaction, with $\mathrm{SO}_{2}$ concentration increasing, sulfides would form in the corrosion products. Therefore, the oxidation kinetics of GH984G followed different kinetics law in various $\mathrm{SO}_{2}$ concentration and corrosion rate accelerated with $\mathrm{SO}_{2}$ concentration increasing. 


\section{Conclusions}

GH984G have shown good corrosion resistance under the corrosion test condtions with difference $\mathrm{SO}_{2}$ concentration. With the $\mathrm{SO}_{2}$ concentration increasing, the corrosion of this alloy accelerated. The $\mathrm{Cr}_{2} \mathrm{O}_{3}$-rich scale with small amount of $\mathrm{TiO}_{2}$ formed on the sample surface under the test condtions. The $\mathrm{Cr}_{2} \mathrm{O}_{3}$-rich scale could inhibit $\mathrm{SO}_{2}$ penetration. Therefore, this scale showed good corrosion resistance in flue gas environment.

\section{REFERENCES}

[1] Abe, F. \& Araki, H., et al. 1987. The role of aluminum and titanium on the oxidation process of a nickel-base superalloy in steam at $800^{\circ} \mathrm{C}$. Oxidation of metals 27(1-2): 21-36

[2] Andersen, A.G. \& Kofstad, P. 1995. Reactions of chromium in SO2-containing atmospheres. Oxidation of metals 43(3-4): 301-315

[3] Aung, N.N. \& Liu, X.B. 2014. Effect of temperature on coal ash hot corrosion resistance of Inconel 740 superalloy. Corrosion Science 82: 227-238

[4] Evans, N. \& Maziasz, P., et al. 2004. Microstructure and phase stability in INCONEL alloy 740 during creep. Scripta materialia 51(6): 503-507

[5] Gillot, B. \& Radid, M. 1990. Corrosion in SO2 of chromium and manganese at high temperature. Oxidation of metals 33(3-4): 279-299

[6] Guo, J. \& Du, X. 2005. A superheater tube superalloy GH2984 with excellent properties. Acta Metallurgica Sinica -chinese edition- 41(11): 1221

[7] Hussey, R. \& Graham, M. 1996. The influence of reactive-element coatings on the high-temperature oxidation of pure-Cr and high-Cr-content alloys. Oxidation of metals 45(3-4): 349-374

[8] Rösler, J. \& Götting, M., et al. 2003. Wrought Ni - Base Superalloys for Steam Turbine Applications beyond $700^{\circ}$ C. Advanced Engineering Materials 5(7): 469-483

[9] Tan, M.L. \& Wang, C.S.,et al. 2014. influence of Ti/Al ratios of gamma coarsening behavior and tensile properties of GH984G alloy during long-term thermal exposure. Acta Metallurgica Sinica 50(10): 1260-1268

[10] Viswanathan, R. \& Henry, J.,et al. 2005. US program on materials technology for ultra-supercritical coal power plants. Journal of Materials Engineering and Performance 14(3): 281-292

[11]Wang, C.S. \& Wang, T.T.,et al. 2014. Thermal Stability of a New Ni-Fe-Cr Base Alloy with Different Ti/Al Ratios. Journal of Materials Science \& Technology 31: 135-142

[12] Wang, S. \& Du, X., et al. 1998. Changes of carbides during long term aging in GH 984 alloy. Transactions of Metal Heat Treatment(China) 19(3): 36-41

[13] Wang, T.T. \& Wang, C.S., et al. 2014. Microstructure evolution and mechanical properties of GH984G alloy with different $\mathrm{Ti} / \mathrm{Al}$ ratios during long-term thermal exposure. Materials \& Design 62: 225-232

[14]Zhong, Z. \& Gu, Y.,et al. 2013. A new wrought Ni-Fe-base superalloy for advanced ultra-supercritical power plant applications beyond $700^{\circ}$ C. Materials Letters 109: 38-41 